\title{
WORKING ABILITY OF THE PARAPLEGICS
}

By Yutaka Nakamura, M.D., Director, Japan Sun Industries

\section{INTRODUCTION}

WhEN the Olympics for the Paralysed were held in Tokyo in 1964, I supervised the Japanese team. Most foreign competitors had been rehabilitated back into society, while Japanese competitors were still patients in hospitals. I decided to organise a working place for wheelchair invalids.

\section{TABLE I}

Classification of the handicapped

\begin{tabular}{|l|c|c|c|}
\hline \multicolumn{1}{|c|}{ Disease } & \multicolumn{2}{|c|}{ Sex } & Total \\
\hline Spinal injuries & Male & Female & \\
\hline Cerebral palsy & 53 & 5 & 58 \\
\hline Polio & 70 & 29 & 99 \\
\hline $\begin{array}{l}\text { Progressive } \\
\text { Muscular dystrophy }\end{array}$ & 7 & 13 & 38 \\
\hline Cong. hip dislocation & 2 & 3 & 5 \\
\hline Deaf & 7 & 6 & 13 \\
\hline Amputee & 7 & 2 & 9 \\
\hline Spine tbc. & I I & I & I2 \\
\hline Miscellaneous & 24 & I2 & 36 \\
\hline Total & 206 & 74 & 280 \\
\hline
\end{tabular}

In October 1965 Japan Sun Industries were founded and have been operating successfully ever since. Now I know paraplegics can be good workers, provided full medical care is available with suitable administration. It is, of course, necessary to provide suitable living and working conditions for them. We have the cooperation of engineering science to supplement our medical rehabilitation of the seriously handicapped. 


\section{JAPAN SUN INDUSTRIES}

Japan Sun Industries is the largest factory in Beppu city and 280 handicapped persons are employed on a commercial basis (Table I) grossing about three million dollars annually. Forty per cent. of them are wheelchair users.

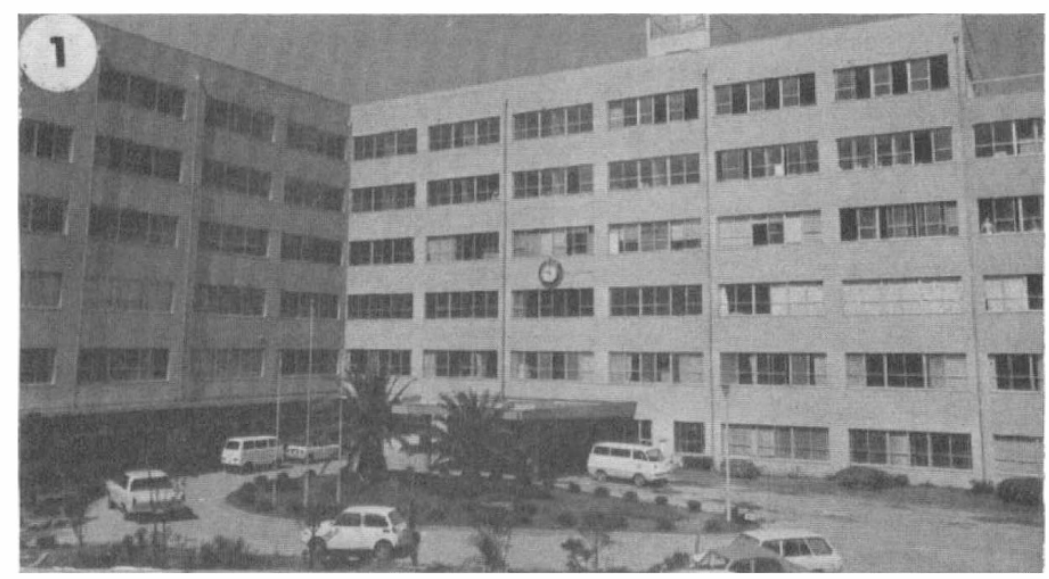

FIG. I

View of Japan Sun Industries.

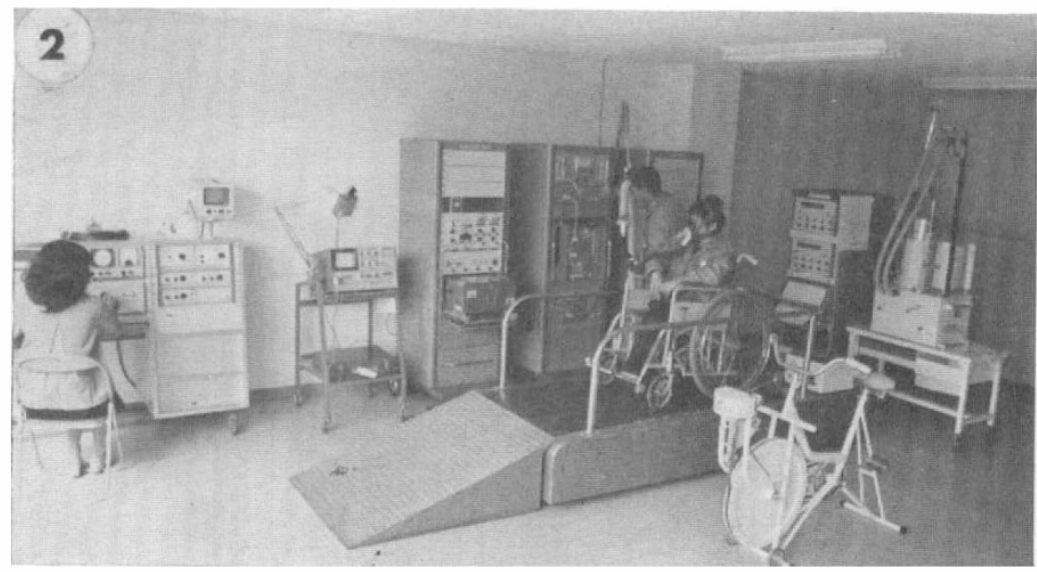

FIG. 2

Physiological room in Human Resources Institute.

We have three factory buildings: The main building, the Human Resources Institute and Omron Taiyo Electronics Co., as well as a gymnasium, swimming pool, hot spring bath, bank, barber shop, etc. (fig. I).

Seven years ago we started in a barrack with about to wheelchair users. We had always dreamed of the present state and most of the great success and development has been made by the Human Resources Institute (fig. 2).

From the very beginning, our aim was that these severely disabled should become tax-payers, and now in the Omron Taiyo Electronics Co. the wheelchair 
users are the share-holders (fig. 3). The manager is a wheelchair user, and they themselves run the company, in which 50 handicapped persons assemble the electric parts (fig. 4).

Now the International Training Institute has been completed. This Institute is for persons from foreign countries as well as Japan who want to study rehabilitation in the Japan Sun Industries.

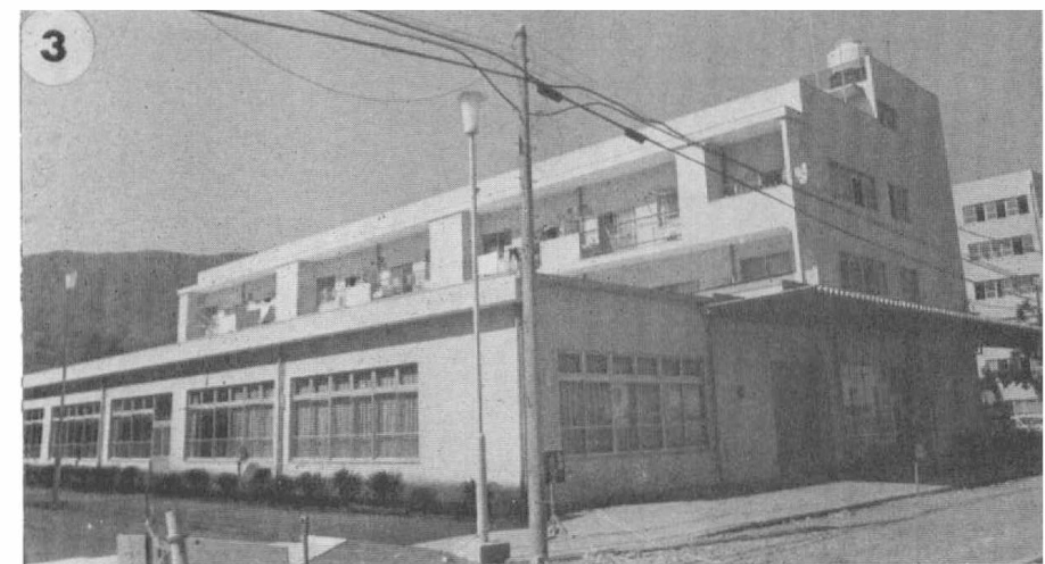

Fig. 3

The whole view of Omron Taiyo Electronics Co.

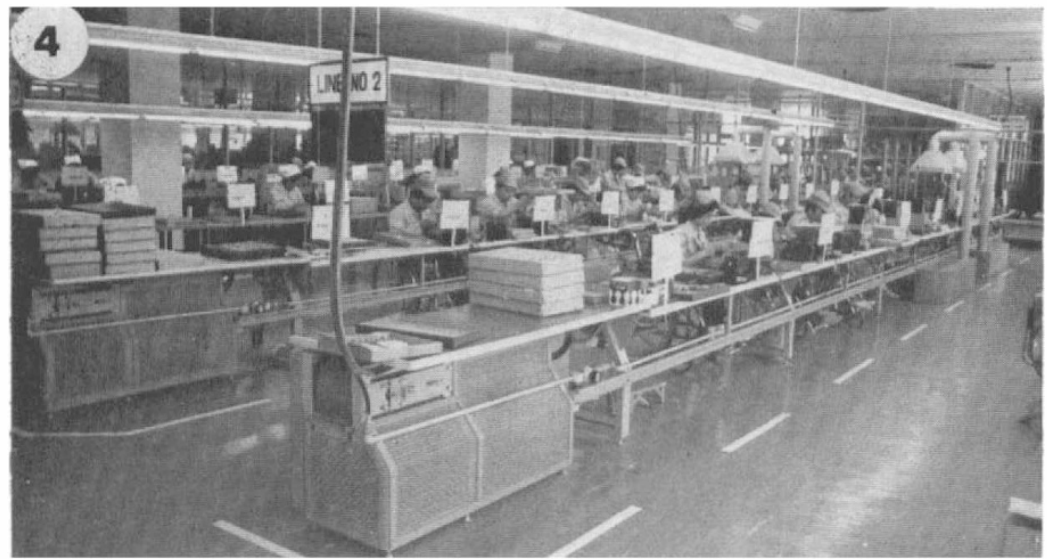

Fig. 4

Assemblying work of electric parts in Omron Taiyo Electronics Co.

\section{PHYSICAL CAPACITY}

The graph shows the physical measurements of the handicapped in Japan Sun Industries (Table II). These are much inferior to the able-bodied, but among the handicapped, those with spinal cord injuries have the best physical measurements. When wheelchair users work, it is necessary for them to have enough power in the upper half of the body (Table III). 
The load that can be lifted by bending the elbow joint from the extension position was measured, i.e. the flexor power (fig. 5) and also the endurance power of the arms. Spinal workers are the strongest, in fact they are stronger than the able-bodied.

The respiratory and circulatory functions were measured by respirometer, cardiograph, breath-analyser, etc., in sitting position and following loading on a

\section{TABLE II}

Average physical measurement

\begin{tabular}{|c|c|c|c|c|}
\hline & $\begin{array}{l}\text { Spinal } \\
\text { injuries }\end{array}$ & $\begin{array}{c}\text { Cerebral } \\
\text { palsy }\end{array}$ & $\begin{array}{l}\text { Progressive } \\
\text { muscular } \\
\text { dyst. }\end{array}$ & Able-bodied \\
\hline Age & 30 & 29 & 23 & 28 \\
\hline Height (cm.) & $163 \cdot 0$ & I $54 \cdot 2$ & I $54 \cdot 2$ & $165 \cdot 2$ \\
\hline Weight (kg.) & $48 \cdot 0$ & $45 \cdot 9$ & $48 \cdot 2$ & $60 \cdot 6$ \\
\hline Girth of chest $(\mathrm{cm})$. & $87 \cdot 0$ & $80 \cdot 9$ & $79 \cdot 8$ & $87 \cdot 4$ \\
\hline Girth of upper arm (cm.) & $26 \cdot 0$ & $25 \cdot 0$ & $19 \cdot 1$ & $26 \cdot 0$ \\
\hline Girth of fore-arm (cm.) & $25 \cdot 0$ & $23 \cdot 4$ & $2 I \cdot 9$ & $25^{\circ} 0$ \\
\hline Girth of wrist (cm.) & $17 \cdot 0$ & $I 6 \cdot I$ & $15 \cdot 0$ & $16 \cdot 0$ \\
\hline
\end{tabular}

TABLE III

\begin{tabular}{|c|c|c|c|c|c|c|}
\hline \multirow{3}{*}{ Disease } & \multicolumn{4}{|c|}{ Power } & \multirow{2}{*}{\multicolumn{2}{|c|}{$\begin{array}{l}\text { Endurance } \\
\text { (seconds) }\end{array}$}} \\
\hline & \multicolumn{2}{|c|}{$\underset{(\mathrm{kg} .)}{\text { Grasping power }}$} & \multicolumn{2}{|c|}{$\begin{array}{l}\text { Flexor power } \\
(\mathrm{kg} .)\end{array}$} & & \\
\hline & Right & Left & Right & Left & Right & Left \\
\hline Spinal injuries & $38 \cdot 9$ & $39 \cdot 0$ & $28 \cdot 8$ & $28 \cdot 6$ & 240 & 210 \\
\hline Cerebral palsy & $23 \cdot 5$ & $19 \cdot 2$ & $6 \cdot 9$ & $6 \cdot 8$ & I32 & 55 \\
\hline Polio & $32 \cdot 0$ & $32 \cdot 0$ & $19 \cdot 5$ & $19 \cdot 2$ & I 28 & 146 \\
\hline $\begin{array}{l}\text { Progressive } \\
\text { Muscular dystrophy }\end{array}$ & I 5.4 & I $4 \cdot I$ & 0.4 & 0.5 & 0 & 0 \\
\hline Spine tbc. & $35 \cdot 0$ & $34 \cdot 0$ & $16 \cdot 5$ & $15 \cdot 8$ & I 55 & 63 \\
\hline Able-bodied & $36 \cdot I$ & $38 \cdot 0$ & $24 \cdot 2$ & $2 I \cdot 3$ & 135 & I 28 \\
\hline
\end{tabular}

I I $/ 2-0$ 
treadmill. No special change was found and there was no problem in respiratory and circulatory functions at all.

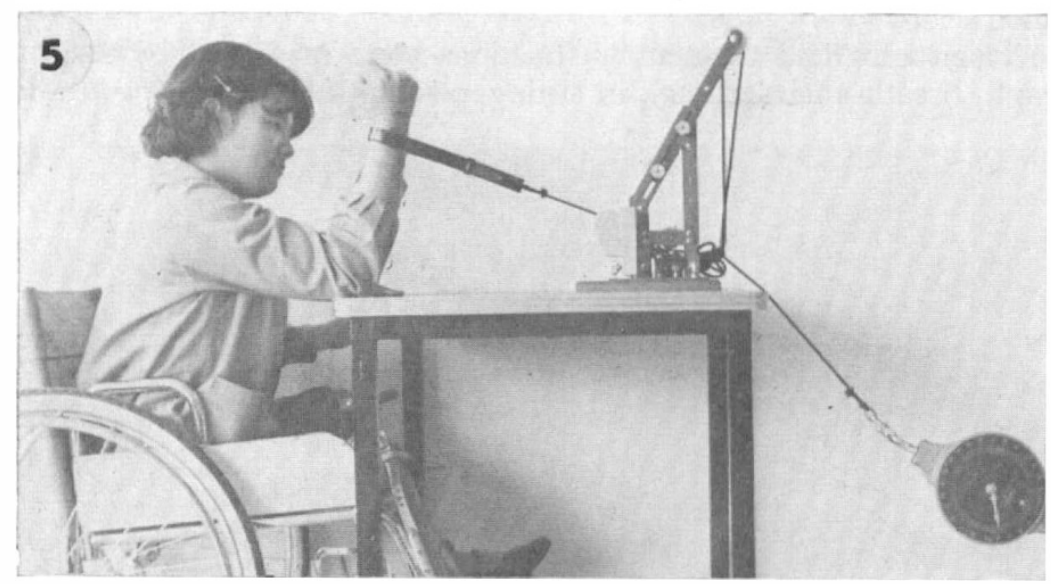

FIG. 5

Flexor power measured what load they can lift by bending one elbow joint from the extension position.

\section{TABLE IV}

Average reach

\begin{tabular}{|ll|c|c|c|}
\hline & & $\begin{array}{c}\text { Horizontal } \\
(\mathrm{cm} .)\end{array}$ & $\begin{array}{c}\text { Forward } \\
(\mathrm{cm} .)\end{array}$ & $\begin{array}{c}\text { Sideway } \\
(\mathrm{cm} .)\end{array}$ \\
\hline Spinal injuries & $\left\{\begin{array}{l}\text { Maximum } \\
\text { Comfortable }\end{array}\right.$ & 77 & 87 & 75 \\
\hline Celebral palsy & $\left\{\begin{array}{l}\text { Maximum } \\
\text { Comfortable }\end{array}\right.$ & 73 & 69 & 40 \\
\hline Polio & $\left\{\begin{array}{l}\text { Maximum } \\
\text { Comfortable }\end{array}\right.$ & 74 & 62 & 66 \\
\hline Progressive & $5 \mathrm{I}$ & $8 \mathrm{I}$ & 39 \\
\hline muscular dystrophy & $\left\{\begin{array}{l}\text { Maximum } \\
\text { Comfortable }\end{array}\right.$ & 76 & 88 & 68 \\
\hline Spine tbc. & $\left\{\begin{array}{l}\text { Maximum } \\
\text { Comfortable }\end{array}\right.$ & 72 & 58 & 70 \\
\hline
\end{tabular}

\section{REACH}

The handicapped in wheelchairs are limited in their work in reaching objects. To raise the efficiency with the least effort, suitable working space was established by measuring the reach (Table IV). Maximal and comfortable reach in horizontal, 
forward and sideways direction to establish the best position for the switch or lever of every machine was measured. Spinal workers were found to have the best reach. The hand lever with a long stroke, for example, needs much energy, so it should be remodelled for its use by wheelchair users. The motor should be placed on the working table and within comfortable reach.

\section{PSYCHOLOGICAL FACTORS}

The handicapped with congenital or acquired handicaps sometimes have medical treatment for long periods and may have had little vocational, economical and domestic opportunities. Moreover, they have few opportunities of attending school or rehabilitation. Being over-protected in the past, psychological imbalance develops. Psychological investigations were performed with the aid of the Cornell Medical Index. Investigations were done three times: first after admission, then after 2 months and after I year.

At first, 40 per cent. showed neurotic signs. They felt uneasiness to the new surroundings and mental fatigue and also unfitness to the new work.

At the third investigation, after I year, those persons who showed neurotic signs decreased to 23.8 per cent. Relaxation to work, and the confidence that they could work as well as the able-bodied, if they were given a chance to do so adjusted to their handicap and greatly improved their mental condition.

\section{FATIGUE}

When many kinds of handicapped persons work on a conveyor system, there will be many factors producing fatigue. It is very difficult to measure fatigue objectively and in the past this has been assessed by combining various methods. Reported here are investigations by questioning and the flicker test. Productivity decreases with fatigue, and, therefore, the quality of the articles gets worse and, being conscious of fatigue, one needs a lot of effort to maintain the efficiency of work.

(A) Investigation by Questioning. The investigation was carried out by the Fatigue Scale of the Industrial Fatigue Research Committee of the Japan Association of Industrial Health. There are three groups in the scale (a) physical symptoms $(b)$ mental symptoms $(c)$ neuro-sensory symptoms. Each group had io questions. The scale paper was given to the handicapped and checks were done before and after work if they had any subjective symptoms within the review of any articles. The checks were counted and the subjective symptom rate was established by the formula:

$$
\text { Subjective symptom rate }=\frac{\text { Number of checks }}{\text { IO days tested }} \times \text { IO० per cent. }
$$

In a woodwork factory 30 per cent. male workers showed more increase in physical symptoms than the standard rate and, therefore, we knew that the work was too heavy for them. As to the mental symptoms, 24 per cent. showed higher degrees than the standard.

In each category the following symptoms were the most frequent: 
(i) Physical symptoms: tiredness in some parts of the body.

(ii) Mental: feeling the brain 'hot or muddled'.

(iii) Neuro-sensory: strain in the eyes.

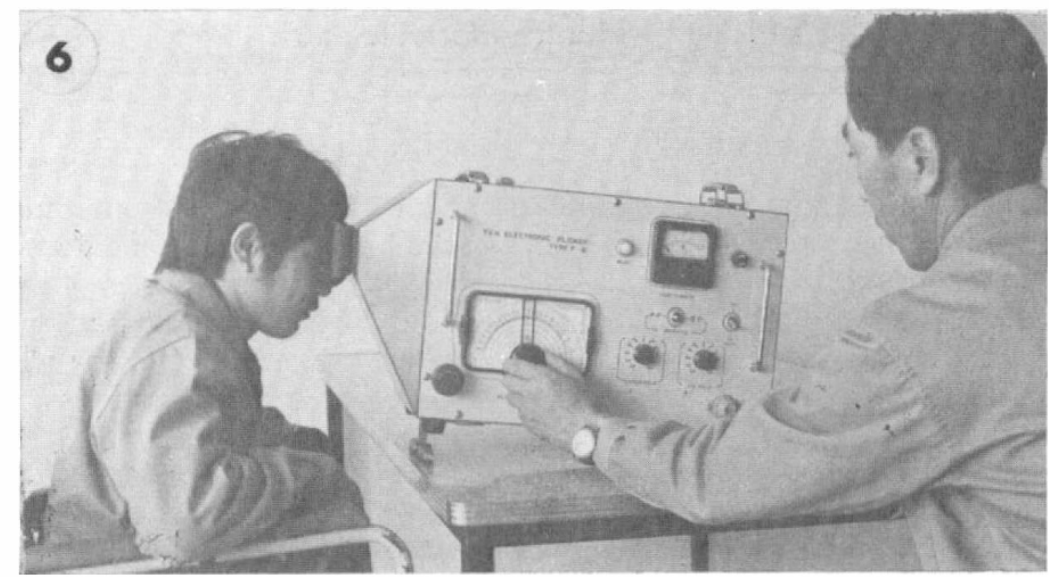

FIG. 6

Flicker test.

TABLE V

Rate of absenteeism (\%)

\begin{tabular}{|l|c|c|c|c|c|c|}
\hline \multicolumn{1}{|c|}{ Disease } & I966 & I967 & I968 & I969 & I970 & I97I \\
\hline Spinal injuries & $4 \cdot 9$ & $9 \cdot 4$ & I0.9 & $4 \cdot 3$ & $4 \cdot 2$ & $4 \cdot 7$ \\
\hline Cerebral palsy & $5 \cdot 8$ & $6 \cdot \mathrm{I}$ & $7 \cdot 8$ & $9 \cdot \mathrm{I}$ & $5 \cdot 7$ & $7 \cdot 3$ \\
\hline Polio & $5 \cdot 3$ & $4 \cdot \mathrm{I}$ & $6 \cdot 3$ & $4 \cdot 6$ & $4 \cdot 9$ & $2 \cdot 0$ \\
\hline $\begin{array}{l}\text { Progressive } \\
\text { muscular dystrophy }\end{array}$ & & $3 \cdot 2$ & $3 \cdot 9$ & $3 \cdot \mathrm{I}$ & $3 \cdot 0$ & $5 \cdot 2$ \\
\hline $\begin{array}{l}\text { Spine tbc. } \\
\text { Miscellaneous }\end{array}$ & $5 \cdot 6$ & $4 \cdot 8$ & $6 \cdot 3$ & $4 \cdot 6$ & $4 \cdot 7$ & $4 \cdot 8$ \\
\hline \multicolumn{1}{|c|}{ Total } & $6 \cdot 7$ & $5 \cdot \mathrm{I}$ & $8 \cdot 4$ & $5 \cdot \mathrm{I}$ & $5 \cdot 3$ & $6 \cdot 4$ \\
\hline
\end{tabular}

(B) Flicker Test (fig. 6). The flicker test is one of the objective ways to measure fatigue. It is a visual method of judging nerve centre fatigue. The flicker test was made in a woodwork factory over a period of one month. The test was made before and after work and the daily and weekly change rate of the flicker was measured. Changes of the flicker rate in a day or a week were only slight and it was concluded that this kind of work was not as hard for the handicapped as it appeared to be. There were some differences between investigation by questioning and the flicker test. 
The results showed that the handicapped, given conditions adjusted to their disability, can be as good workers as the able-bodied.

\section{PREVENTION OF COMPLICATIONS}

In a modern conveyer system, production will greatly decrease with absenteeism. Therefore, we should do our best to prevent workers from becoming ill. Table $\mathrm{V}$ shows the rate of absenteeism per year.

When spinal injured are engaged in work while sitting in wheelchairs, pressure sores may develop in the paralysed parts of the body. This results in secondary infection and causes them to be absent from work for a long time. In 1969 the

FIG. 7

The wheel-chair with transparent plastic seat to observe the skin condition and measure the skin temperature.

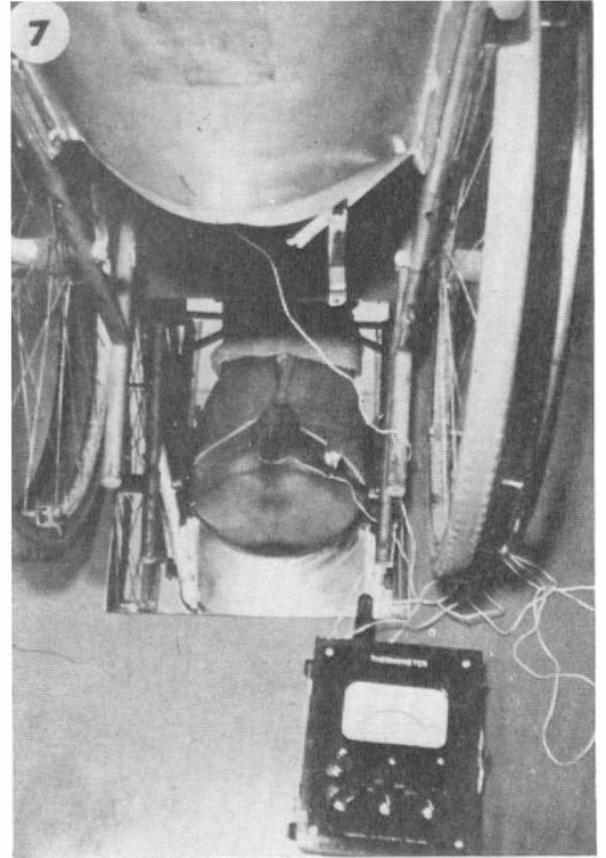

rate of absenteeism of spinal injured was I0.9 per cent., most of which being caused by pressure sores and other complications. Therefore, we examined the methods of preventing pressure sores.

In order to do this we first changed the seat of the standard wheelchair into one of transparent plastic in which we introduced 40 holes of $0.5 \mathrm{~mm}$. diameter and placed a mirror underneath (fig. 7). With this apparatus we examined the ischaemic condition of the skin of the most pressed regions. Furthermore, the changes of skin temperature were measured at five points; on the right and left sides around the ischial tuberosity by an electro-thermometer. We found that the ischial tuberosity was the most pressed area. The colour of the skin changed from dark-red to livid. The regions of the greater trochanter, scrotum and prostatic part of the urethra also showed signs of pressure.

The skin temperature around the region of the ischial tuberosity lowered and the average lowering of temperature in 2 hours was $4^{\circ} \mathrm{C} .-5^{\circ} \mathrm{C}$. in complete lesions 
(Table VI) and ${ }^{\circ} \mathrm{C} .-3^{\circ} \mathrm{C}$. in incomplete lesions (Table VII). However, by pushing up their bodies using the arm-rests of the wheelchair every 2 hours, rapid recovery of the temperature was recorded.

The chief factor in developing pressure sores is ischaemia in the pressure area.

TABLE VI

Change of Skin Temperature in Buttocks (Th. I2. Complete Lesion)

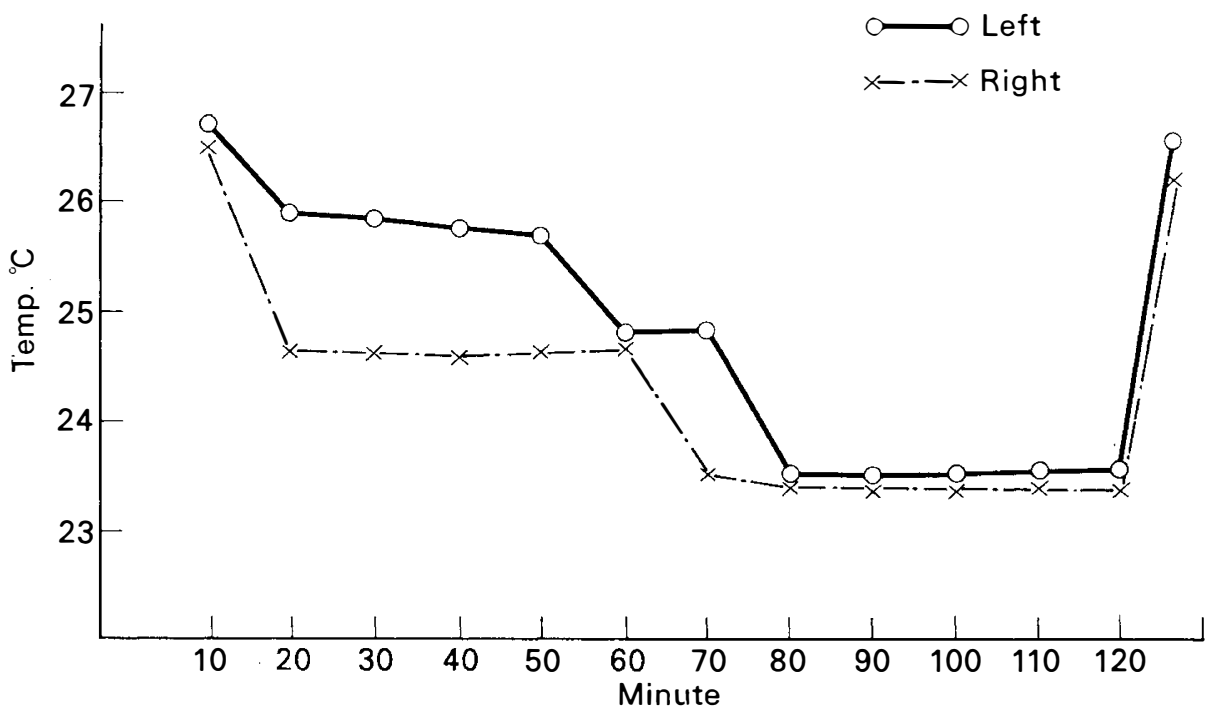

TABLE VII

Change of Skin Temperature in Buttocks (Th. I2. Incomplete Lesion)

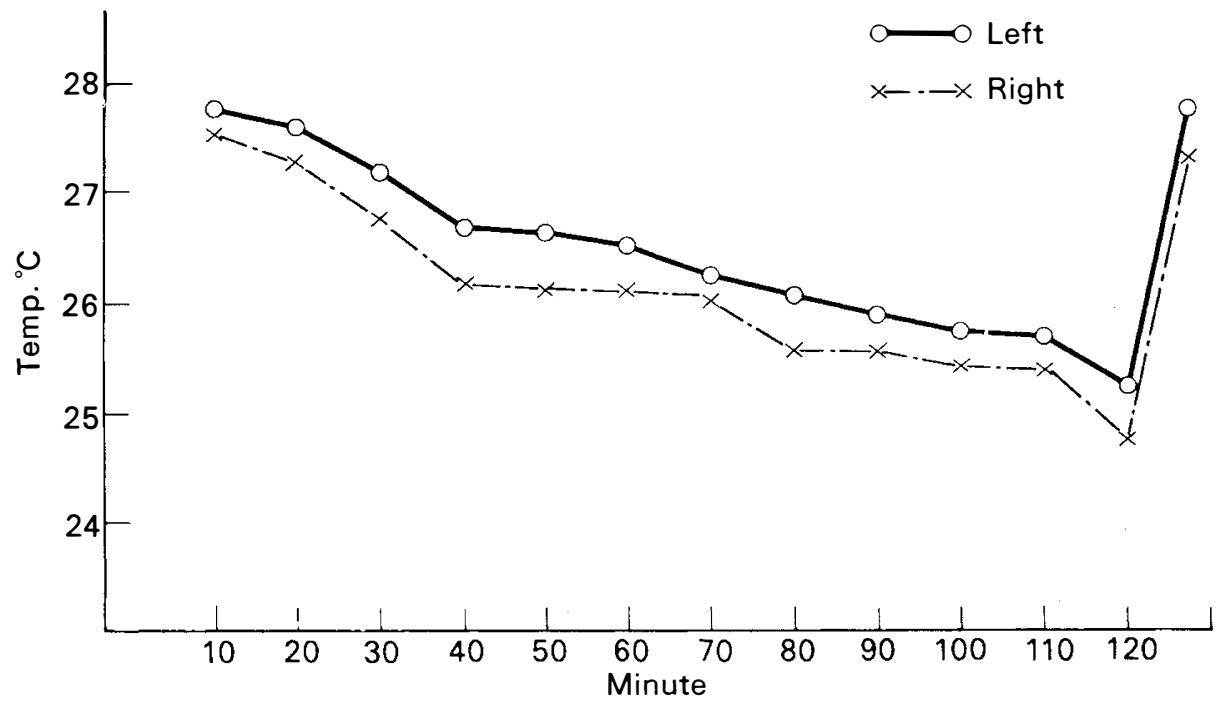


Therefore, when spinal injured are at work, it is imperative to do regular push-ups or massage of the region of the ischial tuberosity or greater trochanter and also to protect them by using proper rubber cushions.

In our workshops, we have three push-up times:- at Io a.m., I2 noon, 3 p.m.,

TABLE VIII

Comparison of absenteeism and wage

\begin{tabular}{|l|c|c|}
\hline & $\begin{array}{c}\text { Rate } \\
\text { of } \\
\text { absenteeism }\end{array}$ & $\begin{array}{c}\text { Wage } \\
\text { per } \\
\text { month }\end{array}$ \\
\hline Spinal injuries (sportsman) & $4 \cdot 0 \%$ & $\$ 132$ \\
\hline Other spinal injuries & $5 \cdot 7 \%$ & $\$ 108$ \\
\hline
\end{tabular}

FIG. 8

Moving lane to the second floor.

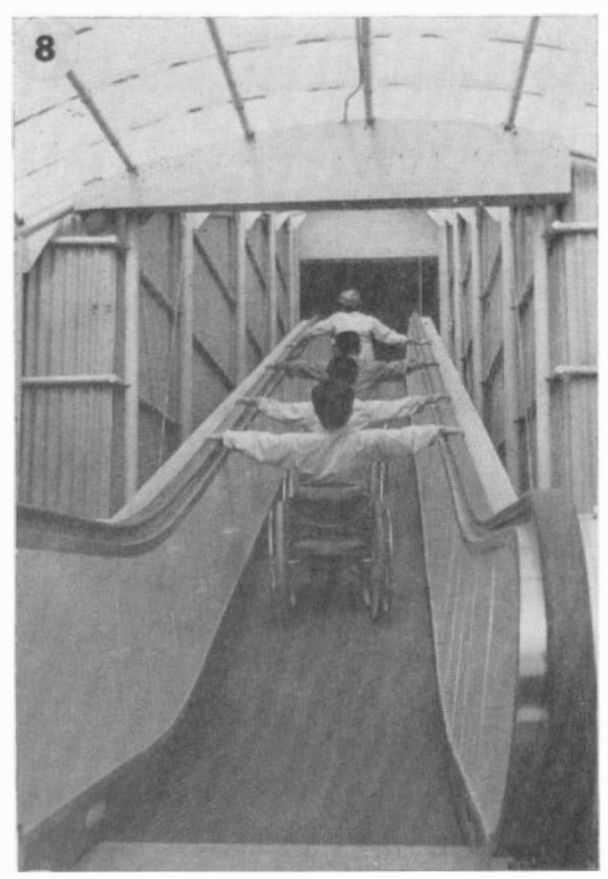

the workers do their push-ups with music in the background. Once a week we have pressure sore inspection by a doctor, also of underwear and bed-making care by a nurse. Every day their reports are given.

We have, of course, the periodic tests such as urine tests, including $\mathrm{PH}$, bacteria, and X-ray of kidney and bladder, I.V.P., residual urine test, etc.

We have also a lot of sports training in the same way as practised at Stoke Mandeville. We found that a good sportsman is a good worker. Table VIII shows a comparison of the rate of absenteeism and wages between sportsman workers and common workers. 
Improvement of the Living Conditions in the Working Area. Much difficulty is encountered in finding help to operate a factory on a commercial basis. Everything should be adjusted to the handicapped to enable them to fend for

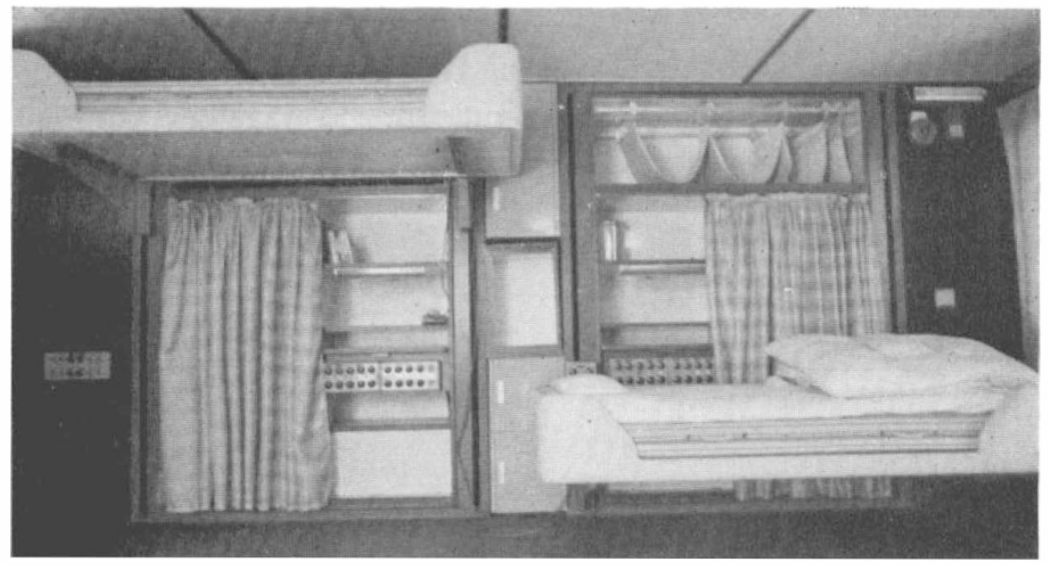

Fig. 9

Fold-away beds.
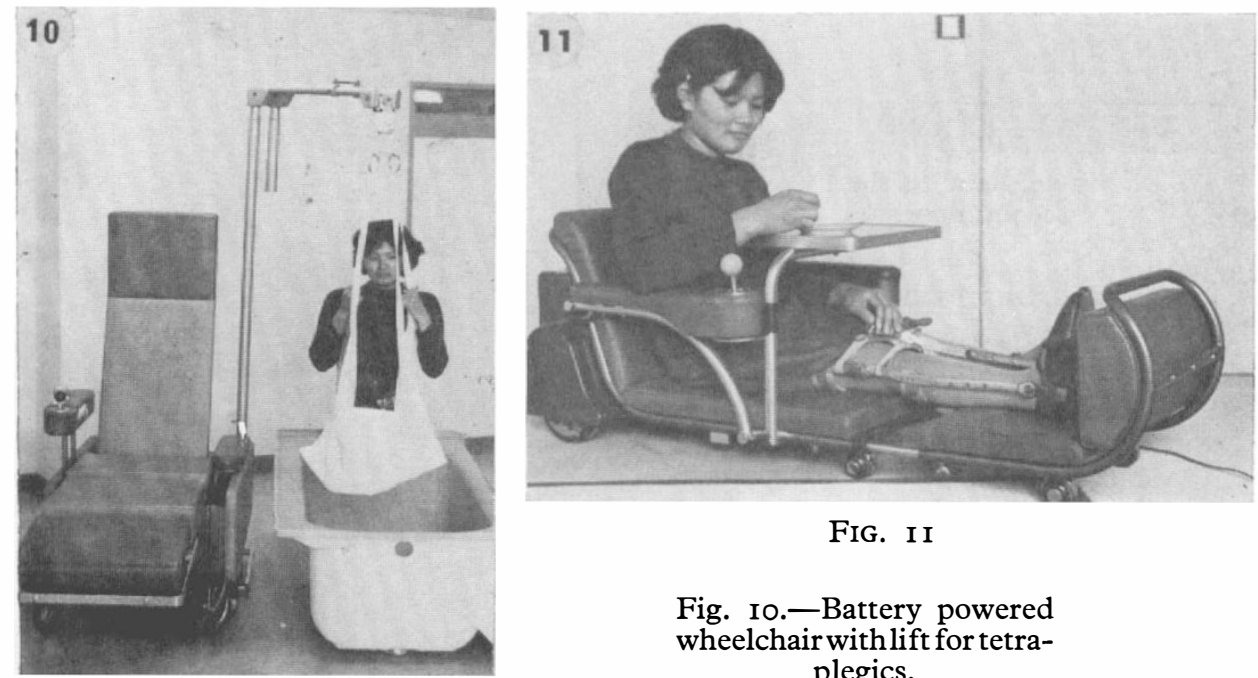

FIG. II

Fig. I0.-Battery powered wheelchair withlift for tetraplegics.

FIG. IO

Fig. I I.-Electrically powered wheelchair for tatami-mats. Standard wheelchair is not suitable for Japanese style house with tatami-mats.

themselves. Every building should be easily accessible for wheelchair users. The bath, for example, has to be the same level with the seat of the wheelchair. A moving lane to the second floor (fig. 8) and an automatic washer of the wheelchair are other examples which have been installed.

We created the model house 'Tetra-Ace' to enable the tetraplegic with 
complete below C.6 lesion to live by themselves. Every mechanism is operated by ultra sound wave: rotating shelf box, fold-away bed (fig. 9), doors and curtains, volume and channel control of television, toilet and telephone.

We have an electrically powered wheelchair with lift for tetraplegics which facilitates transfer of these high lesions. All the operations for the lift are done by whistle (fig. IO).

In Japan we usually live a tatami-mats life and so standard wheelchairs are not suitable and the electrically powered wheelchair had to be adapted (fig. I I). It is also necessary to remodel every machine and tool to suit the paralysed operator. Plastic injection machines (fig. I2), for example, have been remodelled in 50 parts. The control panel of this machine has been re-positioned so that the

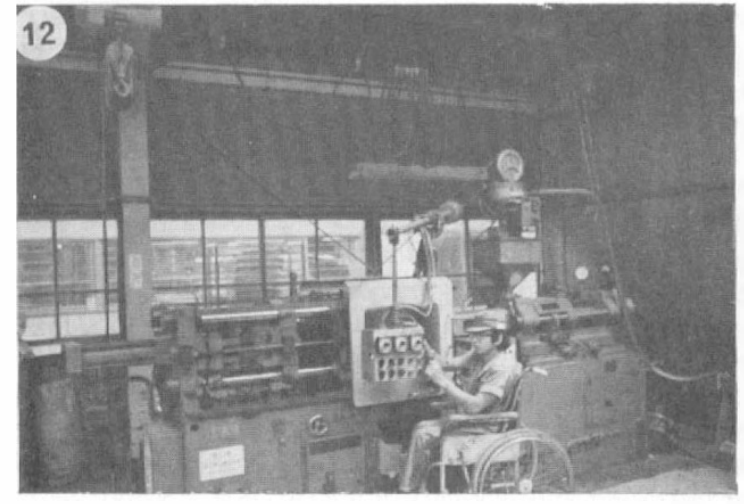

FIG. I2

Fig. 12.-Plastic injection machine remodelled in 50 parts for wheelchair users.

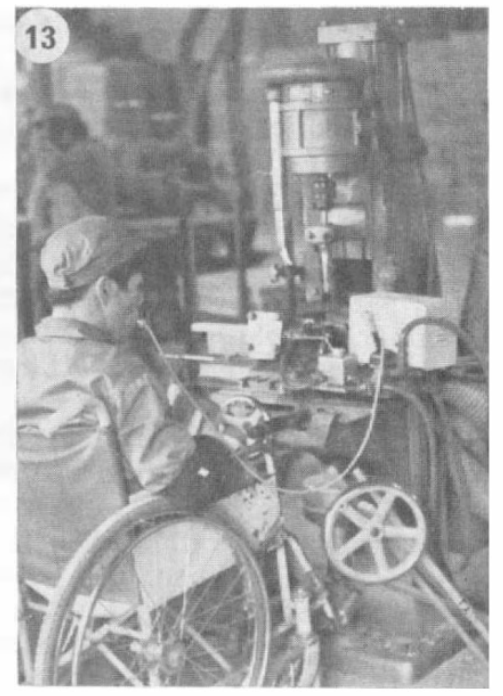

FIG. I3

Fig. 13.-Possum switch on lathe machine for tetraplegic to make three holes by breathing in and out on a board.

workers can freely operate it from the wheelchair with the aid of a possum switch on a lathe. By breathing in or out the machine runs and produces three holes on a board. This is used for the tetraplegics (fig. 13).

\section{SUMMARY}

When we first began the work with Io paraplegics 7 years ago, it was very difficult to find a suitable project. Now the productive ability of the handicapped has been greatly increased by adapting tools, machines, working and living conditions.

We could prove that the paraplegics are excellent workers. Spinal workers are not at all inferior to the able-bodied. We doctors, should give our help and knowledge to them not only at the bedside but also in restoring their working capabilities. 